ISSN: 0210-1696

DOI: https://doi.org/10.14201/scero2021522742

\title{
ÁNGEL RIVIÈRE EN EL CORAZÓN Y EN LA MEMORIA DE LA PSICOLOGÍA ESPAÑOLA Y DEL AUTISMO
}

\section{Angel Rivière in the Heart and in the Memory of Spanish Psychology and Autism}

Miguel Ángel Verdugo Alonso

INICO. Universidad de Salamanca

Ricardo Canal Bedia

INICO. Universidad de Salamanca

María Sotillo Méndez

Universidad Autónoma de Madrid

Maribel Morueco Alonso

Doctora en Psicología. Experta en Autismo

Javier TAMARIT CuAdrado

Confederación Plena inclusión España

Recepción: 21 de abril de 2020

Aceptación: 22 de julio de 2020

\section{Presentación}

E

STA PRESENTACIÓN tiene como finalidad introducir brevemente los textos recibidos durante los meses de abril a junio del año 2020 en recuerdo de Ángel Rivière. Se incluye una breve reflexión inicial introductoria de los textos y, posteriormente, se recogen todos los textos tal cual se recibieron por parte de diferentes personas.

Cuando hace un año empezamos a pensar en alguna manera de rememorar juntos y públicamente las dos décadas del fallecimiento de Ángel Rivière no sabíamos que este 2020 sería un año memorable en sí mismo por una pandemia, que nos traería más 
ausencias y una necesaria manera de aprender a hacer las cosas de modo diferente, que nos obligaría a repensar prioridades y a valorar lo cotidiano. A parar. A pensar y a sentir.

Las líneas que se presentan en este primer artículo, del conjunto de ellos incluido en este número de la revista Siglo Cero, no pretenden ser un nuevo homenaje a la figura de Rivière, ni tampoco pretenden ser un elemento de revisión de su obra, ni tampoco constituyen un documento academicista a pesar de recogerse en una revista científica. Esto es solo la iniciativa de algunas de las muchísimas personas que quisieron y admiraron tanto a Rivière, iniciativa que, desde el primer momento, el Instituto Universitario de Integración en la Comunidad (INICO) recibió gustoso, le dio cabida en esta revista Siglo Cero, y la impulsó con el apoyo valiosísimo de Plena inclusión, para que llegara a la mayor cantidad de personas posible, entre las tantas y tantas personas sobre las que influyó Ángel.

Ángel Rivière fue una figura clave en España para impulsar el estudio científico del autismo y promover el desarrollo de las organizaciones y servicios especializados, así como para alentar una visión positiva del autismo, sensibilizando a la Administración y a la sociedad en general. Hizo un esfuerzo titánico con el que logró inspirar a muchas personas inculcando una visión moderna del trastorno del espectro autista. Su pérdida tan temprana e inesperada nos privó de lo que su compromiso y su genialidad podrían haber aportado a nuestra sociedad para comprender y tratar mejor el autismo en cualquier faceta de la vida, un reto que sigue siendo hoy tan actual y acuciante como lo era hace 20 años. Más allá del autismo, sus aportaciones a diferentes ámbitos de la psicología siguen siendo un referente para generaciones de profesionales, investigadores/as y estudiantes, constituyendo una figura inspiradora que ha formateado las mentes y las maneras de hacer de un amplísimo conjunto de personas en muchos países.

En este artículo atípico de la revista Siglo Cero muchas personas han aportado sus vivencias, sus recuerdos, sus deseos, su imagen creada sobre Ángel Rivière, incluso algunos que no llegaron a conocerle. Muchos de los participantes han señalado la influencia determinante que tuvo en sus vidas. Las aportaciones realizadas, en el espacio limitado de 400 palabras, congregan un conjunto de comentarios, reflexiones, anécdotas, enseñanzas de muy diversa índole en relación con la vida y obra de Ángel Rivière. Los autores de los textos son personas que le han conocido directamente, por haber compartido momentos, proyectos, actividades, o indirectamente a través de sus textos o de cualquier otra forma. Y también, lógicamente, de algunos de sus familiares directos.

Esperemos que estas aportaciones ayuden a dar nuevos pasos en forma de acciones innovadoras que promuevan el avance social y científico en el campo del autismo y las discapacidades del desarrollo, y que fomenten la colaboración para la necesaria reflexión sobre la condición humana, en sus muy diferentes manifestaciones de diversidad, y así, humildemente, contribuyan a una de las más genuinas preocupaciones que tuvo Rivière: mejorar las condiciones de vida de las personas.

Esperemos que de la impronta inspiradora que Rivière nos dejó, de cuyo valor nos hemos ido dando cuenta más intensamente con el tiempo, seamos capaces de lograr 
enlentecer la fuga del tiempo, ocuparnos más en tareas más importantes que urgentes, y procurar contribuir verdaderamente a cambios imprescindibles en las vidas de las personas. Quizás los tiempos de pandemia contribuyan a que nos permitamos el espacio mental para repensar, reordenar prioridades, y que no nos pase otra vez más que "de pronto, ya era tarde".

Como es de imaginar, muchas otras personas manifestaron su intención de participar con sus textos, pero finalmente no pudieron hacerlo; el tiempo u otras barreras han impedido contar con su testimonio. Pero, no importa, sabemos que, aunque no todos hayan podido enviarnos su recuerdo, Ángel, además de estar en la primera página de la memoria científica de la psicología española y particularmente del autismo, permanece también en un lugar muy profundo de nuestros corazones.

\section{Recopilación de textos de Ángel Rivière}

\subsection{Era a mediados de los ochenta...}

Javier Tamarit. Plena inclusión España

Era a mediados de los ochenta y el bullicio de la vida madrileña quedó de pronto silenciado para mí, cuando la conversación dejó de estar centrada en lo cotidiano. A partir de ahí, tan solo escuchaba el torrente de palabras, de emoción y conocimiento que brotaba en Ángel Rivière. Me contaba, se contaba absorto en sí mismo, con la intuición que tenía para descubrir cosas esenciales, los experimentos con primates y la teoría de la mente. Decía que sobre ello se estaban haciendo estudios en autismo y que los resultados eran espectaculares, que se abría un nuevo territorio de exploración del conocimiento en relación al autismo, pero también en relación al desarrollo humano, que... una canica se cambiaba de sitio, que la muñeca no lo sabía, que... Yo, tan solo, escuchaba, rogando en silencio tiempo para procesar todo lo que me decía Ángel, porque sabía a ciencia cierta que su actividad mental en ese momento era la señal de que verdaderamente algo grandioso estaba sucediendo, aunque yo no fuera capaz de 'aprehenderlo' en su totalidad. Apenas un año después, nos lo contó en la conferencia final del congreso de AETAPI (la Asociación Española de Profesionales del Autismo) que tuvo lugar en 1986 en mi tierra, Valladolid. Allí expuso cómo los niños con autismo, si bien en general fallaban, algunos podían, siendo algo más mayores, usar un camino cognitivo lógico, no cognitivo social, para poder procesar y resolver esa tarea de las muñecas, la canica y las falsas creencias, a diferencia de cómo lo hacían los niños y niñas sin alteración en su desarrollo, quienes la resolvían correctamente a los 4 años, aunque, al preguntarles por qué lo sabían, no supieran explicar por qué respondían lo que respondían. Recuerdo, estremecido, que, tras la última palabra de Ángel, el auditorio enmudeció y quedó paralizado, por una vez nadie aplaudió, nadie preguntó... Aún creo que estamos procesando lo que nos dijo y, sobre todo, lo que no nos puede ya decir. 


\subsection{Un maestro en el sentido más bello}

Marta Gil Ferrer. Profesional de apoyo especializado en personas con TEA, extrabajadora de Gaspar Hauser

Un maestro en el sentido más bello. Un ser humano que sabía con sencillez explicar lo más difícil y acercar el conocimiento para entender mejor a esas personas con autismo. En fin, un agradecimiento enorme a su labor.

\subsection{La Misión de Ángel Rivière}

Miquel Ferrà i Martorell. Familiar de persona con TEA. Asociación Gaspar Hauser

Conocí a Ángel Rivière en una situación difícil, cuando en Palma tratábamos de dar educación especial a unos niños con síndrome de autismo, una enfermedad o anomalía que por entonces, década de los 70, sólo afligía a una docena de familias de esa ciudad, las cuales no obtenían respuestas concretas por la vía médica. Pero alguien, comprometido con la misión de divulgar la existencia de este problema y ponerle remedio pese a las limitaciones del momento, llegó a la isla como un soplo de aire fresco.

Pudimos contactar con él en los servicios sociosanitarios y allí, examinando a varios niños, el doctor Rivière nos hizo saber lo que era un chico autista y que una vez puesto en tratamiento, lo que se podía lograr de él. No hubo más camino que el de resignarse a tener lo que se tenía, sin falsas ilusiones o esperanzas. No eran niños raros, de indefinida problemática, sino personas que padecían un síndrome analizado desde 1948 pero que en la España de entonces apenas figuraba en la legislación aquellos días vigente.

Ángel Rivière se había propuesto aquella misión altamente altruista a lo largo y ancho del país. En cierta ocasión, cuando él ya había fallecido y se le dedicó un homenaje en un auditorio universitario, yo dije que el nombre le venía como anillo al dedo ya que su trabajo era angélico y nos facilitaba el poder cruzar el río de nuestras vidas. Alguien tomó esta imagen por el lado cursi. Quizá no era para menos y, a veces, el agradecimiento debería rechazar las exageraciones. Lo sabemos. Los emprendedores humanistas y humanitarios no precisan de epítetos beatíficos. Tienen, como el doctor Rivière, los pies en el suelo y la mente en los engranajes de la ciencia, que, a fin de cuentas, no vive de milagros sino de avances terapéuticos.

Ángel Rivière murió, para sorpresa de todos, relativamente joven, pero dejó el campo abonado, sin esperar agradecimientos de quienes por orgullo todavía no han aprendido a dar las gracias. Es la triste condición humana. Nadie haría nada si esperase, al final de su ruta, una anímica recompensa. Lo mejor es que Ángel Rivière siga permaneciendo en nuestro recuerdo. Nos ha dejado con la lección aprendida y no podemos defraudarle. 
ÁNGEL RIVIÈRE EN EL CORAZÓN Y EN LA MEMORIA

DE LA PSICOLOGÍA ESPAÑOLA Y DEL AUTISMO

M. Á. VERDUGO, R. CANAL, M. ${ }^{a}$ SOTILlO, M. MORUECO Y J. TAMARIT

2.4. He tenido la suerte de conocer a Ángel Rivière y aprender de él...

María Gortázar. Profesional de Centro de atención infantil temprana del Ayuntamiento de Lebrija - Sevilla

He tenido la suerte de conocer a Ángel Rivière y aprender de él no solo sobre el mundo del autismo y la psicología evolutiva, sino también de cómo tratar de ser amable y respetuosa con todas las personas, escuchar empáticamente y ser generosa con mis compañeros de trabajo y con las familias a las que atiendo.

Tristemente no he aprendido a expresarme como lo hacía él. Múltiples veces he leído, releído y subrayado sus artículos y libros sobre autismo y desarrollo infantil, y siempre me asombro de su capacidad para expresar en una sola frase o párrafo todo un cúmulo de contenidos teóricos, y prácticos, que me ayudan a reflexionar y crecer en mi vida profesional como psicóloga de atención infantil temprana. Me admira la precisión de su lenguaje y la profundidad teórica de sus escritos.

Uno, entre tantos, de los aprendizajes clave para mi recorrido profesional, obtenidos gracias a las obras de Ángel Rivière, ha sido sin duda la necesidad de estudiar a fondo las aportaciones de la psicología evolutiva como herramienta de trabajo que me permite conocer mejor el mundo de los trastornos del neurodesarrollo.

Animo a las nuevas generaciones de profesionales a que sitúen el estudio de la evolutiva entre sus principales objetivos de formación. La comprensión de los mecanismos evolutivos que permiten al niño desarrollar las habilidades de interacción social y de comunicación social es una pieza clave para la comprensión del autismo y otros trastornos del desarrollo.

En mi trabajo como terapeuta de atención infantil temprana, siempre trato de tener en cuenta los hitos "normotípicos" del desarrollo cuando reflexiono acerca de las características y necesidades psicoeducativas de uno de mis chicos. Propongo a los nuevos profesionales releer las publicaciones de Ángel Rivière y que realicen para sí mismos "fichas de resumen" como material donde almacenar datos evolutivos relativos a las distintas áreas o componentes del desarrollo infantil.

\subsection{Una semilla que no deja de crecer}

Javier Gómez García. Profesional de apoyo especializado en personas con TEA (APNABI-AUTISMO BIZKAIA. FEVAS Plena inclusión Euskadi)

No conocí a Ángel Rivière. Supe de él. Casualidad. O destino. No lo sé y poco importa. Corría el año 2000, el mundo no se había acabado. Llegan a mis manos unos apuntes de mi madre, sobre Pedagogía Terapéutica. Sus " 20 cosas que nos diría un niño con Autismo" me remueven, ¿principio de una vocación? Niet. No todavía.

Salto temporal: 2005, agosto. Eres mal estudiante y toca apechugar. Hastío estival y apuntes de "El alumno con Espectro Autista". El Katrina arrasa en los informativos y de repente ¡flash! Ahí están los 20 puntos de Ángel. Otra vez. La semilla plantada 
casualmente hace cinco años germina. Quiero saber más sobre el autismo. Algún trabajo de universidad sobre ello y... poco más: inconsistencia de juventud. Años erráticos hacen que no oriente mi vida hacia lo que deseo hacer.

Pasemos más hojas del calendario; estamos en 2009. La semilla de Ángel plantada en el 2000 no ha dejado de crecer leeeentamente. Pero firme. La crisis de las hipotecas subprime empieza a barrer varios millones de empleos; yo tengo suerte y consigo un empleo en Apnabi - Autismo Bizkaia. Aquí sigo. Es casi una década de débil conexión con Ángel y el autismo hasta ese punto exacto de mi vida. Estoy seguro de que su influencia precipitó todo hasta llegar al punto actual. En el camino sus escritos me han acompañado; fuente de consulta y de volver a lo esencial, ante la sobreabundancia de datos y estudios actuales.

Momento actual. Ha pasado poco más de una década. Escribo estas líneas confinado. Es la segunda gran crisis que vive mi generación, millenials de futuro incierto. Se cumplen 20 años del fallecimiento de Rivière, me pregunto qué pensaría de esta situación. Supe de él el año de su fallecimiento, yo con casi 20 años y gracias a sus "20 cosas que...”, ¿casualidad?

En estos tiempos de incertidumbre, de miedos y de expertos en mucho y ejemplos de nada, hay que recuperar a los referentes. Rivière, no te conocí, pero influiste en lo que soy. No necesito haber visto jugar a Di Estefano, para saber que fue un pionero y GRANDE. Como tú.

\subsection{La Mirada de Ángel}

Maribel Morueco. Doctora en Psicología. Jubilada

Ángel, en Palma, el Café Antonio ya no existe, pero sí el Born, la plaza de la Reina, y el mar, al fondo. ¿Te acuerdas? Recién comidos, después de evaluar a 3 niños de 9 , 10 años, con autismo, que no habían recibido ningún tratamiento ni educación, finales de los setenta. Cuánto por hacer, y cuánto trazaste y construiste.

Decirte que, en Baleares, la gran mayoría de los chicos y chicas con TEA están en la Escuela Ordinaria, con mayor o menor intensidad en los Apoyos. Que se detecta a los pequeñines con 18 o 24 meses, y enseguida reciben Intervención Temprana. Las familias aprenden con sus hijos e hijas, en casa, en la calle, en un restaurante. Los profesionales han aprendido mucho, y muy bien, de las mejores fuentes, siguiendo tu estela. Y hay jóvenes con TEA en la UIB. También los hay que diseñan, que dibujan, que exponen en Galerías de Arte. Que hacen teatro, leen poesía, o hablan en el Parlament. Y los chavales más graves..., ¡no dejan de aprender! Y disfrutan de una ciudad viva y abierta que los acoge.

La plaza de Cort se ilumina de azul los 2 de abril, y para muchos también se ilumina el día 12. Ese mes de abril que nos une y nos recuerda el camino andado, trabajado, proyectado. Gracias, mi querido Maestro.

¿Sabes? Nuestros respectivos hijos, son... ¡estupendos! Y tus nietos ¡qué maravilla! Y los nuevos perritos... ¡espléndidos! Leo a Clarice Lispector, y releo, embobada, 
tus artículos del IDEA, la mejor lección de Desarrollo que hayamos podido leer, comprender, y aplicar. Eso es más que un Legado, es la vida misma profesional en las páginas de un libro. La Puerta del Sol está remozada enterita, la Mariblanca luce espléndida, y el Tío Pepe, lo han cambiado de sitio. En tu plaza de la Ópera surge metáfora de una fuente antiquísima de Madrid.

Me he comprado una gabardina.

Al subir la Cuesta de San Ginés, te veo con Inés, revolviendo entre los libros, encontrando imposibles.

Cuando paso por la iglesia de San Francisco, en Palma, me paro siempre, como hacías tú.

Veías el rosetón alto, ornamentado, como su entrada.

Pero a ti, amigo, Profesor, mi querido Ángel, lo que de verdad te gustaba era mirarla como nos mirabas a todos, y sumergirte en la planicie y la hermosura de la inmensidad del marés.

\subsection{Huellas}

María Cristina Coca. Psicología clínica. UAM

Es difícil explicar las "huellas" que ha dejado el profesor Rivière en mí en pocas palabras. Pido perdón por comenzar con mi anecdotario personal. Conocí al Profesor en $1 .^{\circ}$ de Psicología, obligatoria "Historia de la Psicología". La verdad es que la historia no era lo que más interesaba (juventud). Él logró que me interesara tanto con la sencillez y pasión que transmitía que mi entorno me preguntaba si no quería dedicarme a la historia, mis compañeros concluíamos que explicara lo que explicara el resultado era generar interés y motivación en los alumnos.

Y así volvió a pasar: "Psicología del lenguaje", en esta ocasión aunque mi expectativa era muy alta, la superó con creces. Mi admiración profesional y como persona no hizo más que incrementarse. Entre las "huellas" que tuve el privilegio que recoger fue un maestro que nunca olvidaré en mi formación personal y profesional: rigurosidad científica unida al humanismo en el mejor sentido. Estoy segura, lo sé, que no he sido la única privilegiada de haber podido aprender mucho más que los contenidos de una asignatura concreta, una forma de ser y estar en el mundo.

Gracias Ángel. Tu ejemplo continúa y sigue vivo.

\section{8. Ángel, gracias por hacerme sufrir}

Pedro Gortázar. Profesional de apoyo especializado en personas con TEA

Pertenezco a esa generación de estudiantes de Psicología que leían los escritos de Ángel Rivière en caliente, recién cocinados por él y en parte gracias a esos escritos heredé una óptica constructivista a la hora de encarar las dificultades lingüísticas y 
comunicativas, no tanto desde la perspectiva de la categoría diagnóstica, sino la del desarrollo. Citando a Gerber (2003, p. 75).

El especialista en habla y lenguaje con un modelo de base evolutivo no genera ideas de cómo empezar una intervención de lenguaje preguntándose “¿Cómo trabajamos con un niño que es autista?”, sino más bien preguntándose “¿Cómo trabajamos con un niño que está en una etapa preintencional o un niño que está en una etapa prelingüística?”.

Si rebusco dónde se encuentra el núcleo radiactivo de mi pasión por este campo probablemente esté localizado en el estudio de las disarmonías en el desarrollo (lo siento en mi caso en el ámbito de lenguaje en TEA y TEL) y las intrincadas relaciones de procesos y habilidades que sirven de llaves maestras para la intervención.

La palabra pasión etimológicamente proviene del "passio" latino (sufrimiento) y emparentada con el "pathos" griego de significado similar. Otra de las acepciones de "pathos" se refiere al concepto ético de todo lo percibido por la persona, biológica y culturalmente. Gracias Ángel, por hacerme sufrir.

S. Berber (2003). A developmental perspective on language assesment and intervention for children on the autistic spectrum. Top Lang Disorders, 23(2), 74-94.

\subsection{Un elefante sin pintar. Mi homenaje y agradecimiento a Ángel Rivière}

\section{Lidia Rodríguez. Profesora de la Universidad de Castilla-La Mancha (UCLM)}

Esa tarde de marzo llamamos al timbre de aquel majestuoso edificio en la calle Campomanes. Se abrió una enorme puerta, física y simbólica, que cambiaría la vida de Dani para siempre. También la mía.

En 1998 Ángel Rivière era ya catedrático y yo trabajaba como logopeda en Alcorcón mientras completaba mis cursos de doctorado en la Autónoma. Recuerdo perfectamente cada uno de sus estimulantes seminarios y recuerdo perfectamente la tarde en que vi por primeravezala madredeDani, desconsolada, angustiada y devastada, llorandoen miconsulta. No supe qué hacer. Conocía Dani al día siguiente y empecé a verlo todo más claro. Siempre me ha acompañado un profundo sentimiento de agradecimiento al poner en contacto a familias con otros profesionales cuando yo no he sido capaz de ayudar: ¡menos mal que nos tenemos! Y siempre las familias han confiado en los profesionales en los que yo he confiado (léase admirado y amado). No deja de ser un triángulo con un toque platónico que me fascina. ¡Qué chic!

Después de la apertura de aquella puerta abierta de par en par, la tarde en la que Dani y Ángel se conocieron, vinieron días de escucha, valoración y calma. Los primeros en la vida de esa maravillosa familia, merecedora de todo lo bueno.

Mientras observaba a Dani, Ángel dibujó, como increíblemente rápido sabía hacer, el contorno de un elefante gigantesco. No preguntó, no sometió a ningún concurso ni a ningún interrogatorio inquisidor. Sólo le miró y sonrió. "Está vacío” apuntó Dani. Y eso fue suficiente. Reímos todos. La risa como muestra de llanto contenido. 
La noche antes de que todo se quedara sin pintar recibimos un correo electrónico con una palabra como asunto: Ángel. Imagino que el profesor encargado no pudo escribir más. Ni menos. Nos comunicaba que, al día siguiente, creo que martes, no habría clase debido al fallecimiento del profesor Rivière, el mismo que antes era sólo Ángel. El mismo que después lo sería todo.

“Agua y sed, difícil mezcla”. Era la canción que sonaba ese año en la radio a todas horas. Dani la ensayaba con su hermano a la guitarra y se la cantaba después a Ángel en consulta. Uno más de los triángulos fascinantes de esta historia.

¿El tercero? Este regalo-triángulo que estoy sintiendo por parte de Plena inclusión al poder participar en este emocionante homenaje.

Sí. Se nos quedó un elefante por pintar.

\subsection{En una situación difícil}

José Guzmán García. Familiar de persona con TEA. Federación Española del Síndrome X Frágil

Nuestra relación con Ángel Rivière no fue, por desgracia, todo lo duradera que hubiésemos deseado. Le conocimos en una situación difícil, recién recibido el diagnóstico, con todo lo que ello conlleva en cuanto a desconcierto, desánimo..., pero hemos de decir que ha sido el único profesional que nos facilitó pautas concretas de actuación, nos ofreció información precisa y nos proporcionó el sosiego que necesitábamos en esos momentos.

Muchas gracias por su calidez humana y su gran profesionalidad.

\subsection{Mi abuelo era un béroe}

Lola Leturia Rivière. Nieta de Ángel Rivière

Empiezo explicando que yo no tuve el honor de conocer a mi abuelo, pero gracias a mi familia, sobre todo a mi abuela Inés, desde muy pequeña supe muchas cosas de él y lo quiero muchísimo.

Siempre he sabido que mi abuelo era una gran persona y también guapísimo. Mi abuela siempre me contaba y me sigue contando muchas anécdotas sobre él, y yo escuchaba atentamente. Yo creo que mi abuelo era un héroe. Él trabajaba con personas con autismo, especialmente con niños. Estas personas son muy especiales y mi abuelo las trataba como tal.

Me habría encantado conocer a mi abuelo, habría pasado muchos momentos con él y le habría preguntado muchas cosas. Estoy segura de que nos habríamos llevado muy bien.

Este año hago $10^{\circ}$ de secundaria, y en una asignatura del instituto, presenté un trabajo sobre mi abuelo, y mientras investigaba y preguntaba cosas sobre él, supe 
que era una gran persona, que amaba a su familia y un gran profesional en su campo de trabajo. Gracias a él y a mi madre, yo respeto y también quiero a las personas con autismo, y pienso que son maravillosas.

GRACIAS, ABUELO.

\subsection{Añoranza, agradecimiento y cariño}

Mariluz Gutiérrez Araus. Profesora universitaria, familiar de persona con TEA. Fundación Ángel Rivière

Es difícil escribir desde la emoción, pero la emoción es muy productiva como motor de escritura. Y estas líneas salen de un sentimiento de añoranza, mezclado con agradecimiento y cariño, tres grandes emociones.

Ángel apareció en la vida de mi hijo Ricardo y, por tanto, de mi familia, hace cuarenta años. Una situación casual y muy afortunada mirándola con una perspectiva temporal tan extensa. Estaba realizando su tesis doctoral sobre autismo, mientras ejercía como psicólogo en un colegio de Madrid en el que pasó mi hijo sus primeros años (de los 4 a los 7) antes de que cambiáramos a otro lugar de residencia y de colegio.

En este tiempo aparecieron todas las dificultades -en el plano escolar y social- de un niño con un trastorno que nadie sabía definir. Pero a sus 18 años reencontramos a Ángel, quien volvió a ver a mi hijo y le diagnosticó como un "Asperger de libro". Desde entonces cambió a mejor la vida de mi hijo, porque entró en los diferentes programas de apoyo que dirigía nuestro admirado Ángel para los que más tarde se llamarían personas con TEA. Casi semanalmente realizaban actividades novedosas y estimulantes para ellos y para sus familias. Un grupo inicial de padres acudíamos periódicamente a su casa y conocimos a su esposa Inés y a sus hijos. La Universidad Autónoma de Madrid, de la que era catedrático y con la que tenemos una deuda de gratitud, fue el contexto de toda esta peripecia vital.

Ángel ha estado siempre muy presente en el corazón de mi hijo y su muerte representó una gran pérdida. Para todos quienes le conocimos y tratamos, su temprana e inesperada desaparición supuso un duro golpe en nuestras esperanzas vitales. Hubo que continuar, con lentitud y dificultad, un camino que había abierto él apoyando a los niños y jóvenes con síndrome de Asperger.

La colaboración de sus alumnos más notables, actuales profesionales de la psicología en las aulas y en las consultas, ha facilitado el trayecto vital de nuestros hijos hasta estos momentos. Por eso la Fundación Ángel Rivière, nacida para facilitar la vida independiente de adultos TEA, lleva su nombre y, desde ella, quisiéramos llevar su espíritu de entrega a unos adultos cuyas vidas tienen muchas potencialidades en una sociedad que no parece facilitar la superación de sus dificultades.

Siempre estaremos agradecidos a tu persona y a tu vida, querido Ángel Rivière.

Ediciones Universidad de Salamanca / CC BY-NC-ND

Siglo Cero, vol. 52 (2), 2021, abril-junio, pp. 7-42 


\subsection{3. ¿Por qué estáis aquí?}

Juan Pedro García-Cernuda Sainz. Profesional de apoyo especializado en personas con TEA

La primera vez que estuve con Ángel Rivière, él tenía poco más de 21 años, se acababa de licenciar y colaboraba en la Universidad Autónoma de Madrid con el profesor Mesa: Ángel me dio la primera clase de Psicología General, yo tenía 18. Recordándoselo después, me decía "qué vergüenza, a saber qué os diría...”, yo recordaba que preguntaba “¿por qué estáis aquí?”. Quizá sólo él tenía la respuesta precisa si alguien se la hubiera preguntado.

La última vez que le vi y estuvimos charlando fue en Chamberí, tras la presentación de un libro de Gregorio Gómez-Jarabo; nos pusimos al día de lo que estábamos haciendo entonces $y$, antes de despedirnos, quedamos en hablar de la posibilidad de hacer algo juntos sobre derechos, ética y discapacidad; creo que estaba colaborando con Síndrome de Down, entre otras mil cosas.

Excepcional. Que constituye excepción de la regla común, que se aparta de lo ordinario o que ocurre rara vez. Así, excepcional define muy bien a Ángel, que es una persona cercana, de trato cómodo y compañía fácil, excepcional en su quehacer, su pensamiento, trabajo y cotidianidad.

Y generoso; en entornos donde no se prodiga esta virtud, si es que hay alguno en la que abunde.

Recuerdo anécdotas, sin que yo haya tenido trato excesivo con él, ni mucho menos: la presentación de la revista Estudios de Psicología, en el pub La Hemeroteca, frente al colegio de sus hijos; la memorable defensa de su tesis doctoral en la Autónoma, largamente esperada, que, fuera de protocolo, levantó una espontánea ovación de los presentes y del propio y entrañable profesor Pinillos desde el tribunal, que nos advertía a los oyentes que teníamos delante no un enjundioso trabajo de tesis doctoral, sino un tratado de obligada consideración a partir de entonces para el conocimiento de la mente, como así ha sido.

Tuvo deferencias conmigo que no merecía; como hacía con compañeros, colegas o discípulos, con espontaneidad, resaltando sinceramente los méritos más o menos limitados que valoraba con entusiasmo.

Pero, para un académico de su talla, quizá la palabra que, literalmente, mejor le defina sea Genial, de acuerdo a las acepciones que dicta la Real Academia de la Lengua: Placentero, que causa deleite o alegría; sobresaliente, extremado, que revela genio creador; magnífico, estupendo.

Vale. 
ÁNGEL RIVIÈRE EN EL CORAZÓN Y EN LA MEMORIA

DE LA PSICOLOGÍA ESPAÑOLA Y DEL AUTISMO

M. Á. VERDUGO, R. CANAL, M. ${ }^{a}$ SOTILlO, M. MORUECO Y J. TAMARIT

\subsection{Un cariñoso recuerdo, que perdure y continúe el camino emprendido por él}

Marisa Ximénez Embún. Orientadora escolar de Educación Especial jubilada

Tuve la gran suerte de escuchar a Ángel en la UAM como profesor de psicología cognitiva, cautivaba con sus exposiciones. Con él aprendí la teoría de la mente que contaba con tanta pasión. Después en el máster de Logopedia volvió a ser un placer aprender con él mis primeros conocimientos sobre autismo, enganchaban sus clases.

En los diversos congresos se mostraba cercano con cualquiera que se acercaba a él. ¡Qué decir de sus publicaciones, base de tantas investigaciones posteriores! Para mí fue un placer aprender tanto con él y haberle conocido en persona. Un cariñoso recuerdo, que perdure y continúe el camino emprendido por él.

\subsection{La risa de mi padre}

Mario Rivière Marichalar. Hijo de Ángel Rivière

Hace ya 20 años que mi padre nos dejó y no pasa un día sin que le eche de menos. Sé el peso que su trabajo tiene en el campo de la psicología, lingüística e investigaciones sobre el espectro autista y, cómo no, estoy tremendamente orgulloso de ello. He conocido a muchos de sus alumnos o gente que ha estudiado su obra y me han hablado de él con pasión y admiración, pero el Ángel que yo echo de menos es menos conocido.

Mi padre era un hombre cariñoso, profundamente inteligente, comprensivo y divertido, increíblemente divertido. Y esa es la parte de él que más echo de menos: los dos compartíamos una enorme pasión por el absurdo y conocíamos las propiedades curativas de la risa, de dejarse llevar por los caminos del esperpento en busca de una pequeña joya cómica. Los recuerdos que atesoro con más devoción casi siempre están relacionados con una sonrisa cómplice, un desternillante comentario irónico, un estrepitoso estallido de risa o directamente una payasada sin complejos. Era un hombre capaz de comprender y disfrutar lo más complejo y también de gozar como un niño pequeño con un momento cómico profundamente idiota, un chiste increíblemente malo (que en su boca sonaba maravilloso) o una visión absurda que provocaba divertidísimas y brillantes reflexiones.

Pocas veces he reído tanto como reía a su lado y siempre que le recuerdo lo hago con una sonrisa, saboreando esos momentos en los que nos zambullíamos juntos en el disparate para salir a la superficie con una carcajada en el estómago. Ahora mismo, pese a la ansiedad que siempre me produce escribir, me descubro sonriendo, casi al borde de la risa, recordando tantos momentos hilarantes a su lado... Va por ti, padre, sé que, estés donde estés, tu sonrisa está lista para brotar. 


\subsection{Treinta años de amistad}

Juan Delval. Catedrático jubilado

Cuando empezó el curso 1969-1970 me encontré como profesor en la clase de cuarto curso de "Psicología evolutiva" de la Universidad Complutense con un numeroso grupo de muchachos y muchachas que constituían la primera promoción de la recién creada especialidad de Psicología. Era un grupo heterogéneo en el que había algunas mentes brillantes e inquietas, que querían conocer cómo somos los seres humanos. Nos ocupamos, sobre todo, de estudiar cómo empieza a formarse la mente y buena parte del curso estuvo dedicada al nacimiento de la inteligencia durante el período sensorio-motor. Aquellos alumnos hacían preguntas difíciles. Uno de ellos, que tenía ademanes suaves pero que hablaba con firmeza y convicción, se hacía a sí mismo preguntas profundas y nos las trasmitía a los demás. Se llamaba Ángel Rivière y pronto nos hicimos amigos y seguíamos discutiendo al terminar la clase en el bar de aquella facultad ocupada por la policía.

Cuando terminó el curso mantuvimos el contacto y al año siguiente al acabar la carrera le propuse que se incorporara al proyecto de investigación que dirigía en el Instituto de Ciencias del Educación de la Universidad Autónoma desde 1970 en el que estudiábamos el desarrollo del uso de las conectivas lógicas y problemas del razonamiento.

La investigación que realizábamos se vio interrumpida abruptamente cuando algunos fuimos expulsados de la universidad, pero durante todos esos años seguimos manteniendo contacto, y discusiones que Ángel siempre hacía interesantes. Recuerdo abundantes conversaciones acerca de su tesis, que había surgido como una prolongación del proyecto de investigación en el que trabajamos juntos. Se inició con el problema de las series de tres términos Su trabajo se prolongó más de lo que parecía razonable, y cuando discutíamos siempre terminaba tratando de convencerle para que cerrara la investigación, que llevaba camino de convertirse en algo inacabable. Finalmente la defendió en 1984 y dio lugar a un estudio notable sobre el razonamiento y la representación que publicó.

En sus últimos años, cuando nos encontrábamos en la facultad, aunque fuéramos con prisa, siempre se detenía como si tuviera todo el tiempo del mundo para que charláramos un rato. Me llamaba la atención su cordialidad, pues siempre hacía alguna observación amable. Aunque estaba muy sobrecargado de trabajo no había perdido ni un ápice de su entusiasmo y se seguía embarcando en todas las empresas que le parecían interesantes. Su muerte fue un golpe irreparable y algo muy injusto. 
ÁNGEL RIVIÈRE EN EL CORAZÓN Y EN LA MEMORIA

DE LA PSICOLOGÍA ESPAÑOLA Y DEL AUTISMO

M. Á. VERDUGO, R. CANAL, M. ${ }^{a}$ SOTILlO, M. MORUECO Y J. TAMARIT

\subsection{Desde Melilla...}

Juan López. Profesional de Plena inclusión Melilla

Desde Melilla, queremos sumarnos también al reconocimiento profesional a Ángel Rivière, por su labor y su aportación pionera e imprescindible a la calidad de vida de las personas con discapacidad y sus familias. También aprovechamos estas líneas para mandar un emotivo abrazo a la familia Rivière.

\subsection{Un hombre bueno}

Pablo Rivière Marichalar. Hijo de Ángel Rivière

Mi padre era un hombre bueno. Cuando la gente habla de él, suele referirse a su trabajo como psicólogo, y también suelen decir que, además, era un hombre bueno.

Siempre he admirado a mi padre. Él es mi norte intelectual, pero ante todo mi norte moral. Cuando se fue, yo tenía 18 años. Recién fallecido, cuando le recordaba, admiraba en él al académico, o al hombre que luchó para traer la democracia a su país. Siguiendo su estela, me hice científico y me involucré en el activismo. Sin embargo, ahora que tengo dos hijos, mi admiración se centra en su calidad humana. Porque quiero ser para mis hijos lo que él fue para mí. Un referente. Un buen padre. Un hombre bueno.

Nos gustaba jugar al ajedrez. Yo perdí hasta bien crecido. Cuando mis manos llevaban las piezas a lugares peligrosos, él me decía: “¿Seguro?”. Me daba la opción, no la solución. Quería que fuese yo el que la encontrase. Con el tiempo, la encontré, y gané. ¿Cuantas veces? Tan pocas que las atesoro, como atesoro cada recuerdo suyo. En la feria del libro juntos. Paseando entre las casetas, buscando libros: novela negra, psicología... Cuando un libro le interesaba se concentraba con intensidad. Diría que cada cosa la meditaba con intensidad. Una vez fuimos al cine a ver La Lista de Schindler. Pasado un tiempo, cayó dormido. Llegó al ronquido. Yo decía "Papá, despierta”. Y él respondía “SSi estoy despierto!” y volvía a caer. Trabajaba tanto...

Era extremadamente divertido. Cuando venían amigos a casa solía sacar la guitarra y tocar su gran éxito Me gusta el amarillo. Terminábamos cantándola a voces. Amaba pasear. En verano, por los cerros de Ahusín, con Jasón y Merlín. Jamás hizo el menor amago de disciplinarlos. Los quería como eran, asalvajados. Nosotros caminábamos, ellos corrían por los trigales. Se paraba y, sin más, miraba fijamente a lo lejos. A sus perros. Estudiaba lo que hacían. Los amaba genuinamente. Sin más. Era un hombre bueno.

Su cabeza reposando en mi regazo, cuando yo era ya algo más mayor... ¿Dieciséis? No lo sé. No importa. Solo importa el tesoro. Cada recuerdo que tengo de él. ¿Por qué no los hay malos? La explicación es sencilla. No los he borrado. Nunca los ha habido. Porque mi padre era un hombre bueno. 
A menudo cuando quiero hacer algo bien me sorprendo pensando “¿Qué haría papá?”. Quiero hacer lo correcto. “QQué pensaría papá?”. Como se fue muy pronto, hay muchas piezas que me faltan. El puzle no se completa. No puedo saber lo que pensaría. Pero lo intento. Y entonces pienso “¿Qué haría un buen hombre?”. Pues eso haría papá. Porque mi padre era hombre bueno.

\subsection{Ya no pudo ser}

Amparo Gavela. Familiar de persona con TEA

Yo conocí a Ángel Rivière en el primer congreso sobre Síndrome de Asperger que se celebró en Madrid.

Mi hijo acababa de ser diagnosticado y, como casi todas las familias entonces, estábamos muy perdidas.

Recuerdo a una persona muy cercana, que sabía de lo que hablaba y eso ya daba mucha tranquilidad. Tenía un sentido del humor y una forma de comunicar que deja huella.

Cuando diagnosticaron a mi hijo en APNA, estaba Juan Martos y luego nos correspondería otra sesión con Ángel Rivière, que ya no pudo ser.

La noticia de su pérdida me conmocionó.

\subsection{Gran maestro y comunicador}

M. ${ }^{a}$ del Mar Oliver. Profesional de apoyo especializado en personas con TEA

Gran maestro y comunicador.

Transmitía entusiasmo, respeto, generosidad, sabiduría...

Gracias, Ángel, por compartir tus conocimientos y tu humanidad con quienes te conocimos. Han sido una guía en mi trayectoria profesional y en mi vida personal.

\subsection{Un referente}

Miguel Ángel Álvarez. Profesional de apoyo especializado en personas con TEA

Le conocí allá por el año 1991 en un curso de verano de la Universidad de León sobre el trastorno del espectro autista.

Me impactó su explicación sobre la teoría de la mente.

Referente que sentó las bases para tratar a las personas con TEA.

Aún hoy sería necesario reforzar y divulgar sus conocimientos y principios. 
ÁNGEL RIVIÈRE EN EL CORAZÓN Y EN LA MEMORIA

DE LA PSICOLOGÍA ESPAÑOLA Y DEL AUTISMO

M. Á. VERDUGO, R. CANAL, M. ${ }^{a}$ SOTILlO, M. MORUECO Y J. TAMARIT

\subsection{Fue un lujo conocerlo}

Carlos Benigno Esteban. Profesional en servicios de la Administración Pública

En el año 1995 comencé a desarrollar programas de Atención Temprana con niños con TGD, junto a autores extranjeros, destacaban los textos de Ángel Rivière por la profundidad y la cercanía de sus obras. Ángel era y es lo que se consideraba una autoridad en el ámbito del autismo, en la investigación, en el diagnóstico, en el tratamiento, en las orientaciones a las familias y en todo.

Pero de Ángel sobresalía también su valor como persona, su cercanía, su apoyo a las familias y a toda la comunidad.

Una familia de Melilla que yo atendía en Melilla acudió a verlo en Madrid. Y él me llamó a las 11.30 de la noche para comentarme orientaciones para la niña que había diagnosticado y a su familia. Normalmente cundo te llamaban a esas horas en esa época sin móviles era para darte una mala noticia y el sonido de la llamada te asustaba. Esa llamada duró una hora y pocas veces he aprendido tanto en una llamada de teléfono y me ha dado tanta tranquilidad. Tiempo después lo conocí en persona y me impresionó su capacidad y disposición para ayudar a los demás.

Fue un lujo conocerlo.

\subsection{El maestro de todo esto}

Lola López. Profesional de apoyo especializado en personas con TEA

La primera vez que oí hablar de Ángel Rivière fue cuando comencé a trabajar como AL en un aula preferente de TGDs de la CAM. Era interina y tenía que preparar la dichosa programación para las oposiciones. Me dijo mi compañera Beatriz Ruiz Casas (PT y especialista en TEA): "Si quieres empaparte de lo que es autismo tienes que empezar por Rivière, es el maestro de todo esto, es el comienzo de nuestra labor”... Ahí empezó todo. Comencé a leer sus obras y la de su compañero Juan Martos..., comencé a conocer un mundo especial, lleno de interrogantes pero pleno en conocimiento, absolutamente atrayente como un imán atrae un clavo.

Sus 20 conceptos fundamentales, esas 20 citas que son la esencia de sus vivencia y estudios, fueron para mí el motor principal para estar con ellos, con "los autistas". Ángel Rivière me dio la mano, a través de sus libros, para entrar en un mundo maravilloso donde merece la pena estar por todo lo que aprendes: esos pictogramas, esas anticipaciones, esas agendas visuales, todo ordenado y establecido... Eran unas rutinas maravillosas donde comenzabas, cada día, a interactuar con esas personitas tan adorables y especiales.

Aprendí que saben agarrarte por el cuello, que te besan y que te quieren..., que se enfadan contigo, que no miran a la cámara cuando les haces una foto, que están en su mundo pero... contigo... "Merece la pena vivir conmigo"..., merece la pena estar con ellos. 
ÁNGEL RIVIÈRE EN EL CORAZÓN Y EN LA MEMORIA

DE LA PSICOLOGÍA ESPAÑOLA Y DEL AUTISMO

M. Á. VERdUGO, R. CANAL, M. ${ }^{a}$ SOTILlO, M. MORUECO Y J. TAMARIT

\subsection{Nos ayudó a conocer y entender a Nacho}

Concha Calvo. Familiar de persona con TEA

Soy Concha, tengo 46 años y soy hermana de Nacho, persona con TEA que actualmente tiene 47 años, somos de Zaragoza.

Ángel Rivière diagnosticó e hizo seguimiento del caso de Nacho hasta que falleció. Recuerdo los viajes a Madrid 2 veces al año al local de APNA, Ángel nos recibía y dejábamos a Nacho con él, cuando volvíamos hablaba con mis padres. Después de unos días llegaba a casa un informe.

Como familia nos ayudó a conocer y entender a Nacho, adaptarnos en lo que teníamos que adaptarnos y a ponerle límite en lo que había que poner límites. Después de 20 años releo los informes que nos daba y todas y cada una de las recomendaciones que nos hacía siguen siendo hoy válidas y necesarias para Nacho. Cuando las cosas no van bien volver a leerlos nos recuerda cuál es el camino y la dirección que tenemos que seguir.

Actualmente trabajo con alumnado TEA y recuerdo con admiración haber conocido a Ángel y haberlo tenido tan cerca sin yo saber quién era realmente. Entre mis compañeros cuando sale su nombre digo muy orgullosa "yo conocí en persona a Ángel Rivière”. Todavía guardo el póster que APNA publicó en su día: "Qué nos pediría una persona con autismo”. Mi más absoluta admiración hacía él como familiar y como profesional.

\subsection{Teñido de caqui}

Enrique Lafuente. Profesor universitario

Mi recuerdo de Ángel Rivière está inevitablemente teñido de caqui.

Conocí a Ángel en el verano de 1969, en el campamento de La Granja donde ambos hacíamos el servicio militar. Fuimos a caer en la misma compañía, y no tardamos mucho en adquirir una bien ganada fama de descomunal despiste. Era más que evidente que el espíritu militar no era lo nuestro, y las voces de mando de la superioridad solían encontrarnos pensando en otra cosa. Nuestra amistad fraguó en las interminables conversaciones que manteníamos durante los arrestos de fin de semana que compartimos a menudo a lo largo de los dos veranos que duró la "mili”.

Sobre esta base tan improbable logramos construir una relación sumamente estrecha, fraternal, asentada en profundas afinidades intelectuales y morales y cultivada en frecuentes salidas de fin de semana y alguna breve escapada vacacional junto con nuestras parejas de entonces y de siempre, que resultaron haber sido compañeras de Instituto. Recuerdo particularmente unos deliciosos días de Semana Santa pasados al borde del mar, ocupados con grave concentración y muchas risas en la resolución de los problemas de pensamiento planteados por Edward de Bono. 
También en lo profesional hubo de dejarme Ángel una impronta poderosa. En 1974 me propuso como "profesor especial" de Historia de la Psicología en la Universidad Autónoma, lo que supuso mi primera incursión en la docencia de una disciplina a la que iba a dedicar ya en lo sucesivo mi vida académica. Acudía yo a mis clases desde la otra punta de Madrid, directamente desde el cuartel donde hacía mis prácticas de sargento (jotra vez el ejército!) sin tiempo siquiera para cambiarme el pantalón del uniforme. Años después me incorporó a su equipo de la recién fundada revista Estudios de Psicología, en cuyo primer número iba a publicar también yo mi primer artículo.

Las inercias de la vida nos fueron distanciando, pero no importaba: ambos sabíamos que en cualquier momento en que nos reencontráramos podríamos retomar las cosas en el punto exacto donde las habíamos dejado. Así nos sucedió en varias ocasiones, pero no pudieron ser tantas como hubiéramos esperado y querido. La figura de Ángel, como él mismo escribió de la de Vygotski en un libro ya clásico e imprescindible, "cruzó como una furia veloz" la psicología española; pero también nuestras vidas, dejándonos a su paso la estela magnífica de su obra admirable y la tremenda añoranza de su presencia.

\subsection{Un ejemplo a seguir}

Verónica Ferrer. Profesora de pedagogía terapéutica y orientadora

Ángel fue y sigue siendo para mí un ejemplo a seguir. No sólo por su profesionalidad, capaz de profundizar y arriesgar, sino por traspasar la distancia fría y conectar y querer a sus «chavales». El grado de complicidad que podía establecer aún sigue asombrándome e inspirándome como sólo lo pueden hacer los grandes. Se fue demasiado pronto pero su legado continúa. Es imposible de olvidar y no se puede entender la atención a la inclusión en España sin él. Un abrazo y todo mi reconocimiento allá dónde esté.

\subsection{Una bella persona, un excelente profesor, un gran clínico}

Antoni Gomila. Profesor universitario

La muerte, prematura e inesperada, de Ángel Rivière nos arrancó una bella persona, un excelente profesor, un gran clínico, especializado sobre todo en el tratamiento del autismo, un influyente epistemólogo de la Psicología Cognitiva, un investigador inquieto, un generoso formador de investigadores, y un poeta; en definitiva, una persona sensible, comprometida con su trabajo, con su tiempo y con los demás. Un ejemplo estimulante, una referencia.

Conocí a Ángel porque formó parte del tribunal de mi tesis, en 1990. Llegó con los dos volúmenes sobre Parallel Distributed Processing, de Rumelhart y McLelland, 
la llamada biblia conexionista, recientemente publicada. La tesis iba sobre Fodor y su teoría computacional de la cognición, y, aunque era crítica con Fodor, la discusión se prolongó varias horas, en un debate sobre los fundamentos de la cognición y sobre el mejor modo de explicarla. Ángel reivindicaba el interés del estudio de los procesos microgenéticos, tenía una actitud abierta e integradora, estaba al día de los últimos avances, pero estaba comprometido con ciertas ideas fundamentales, como el interés por la microgénesis, en particular por el desarrollo de la función simbólica, la semiosis por suspensión. Por ello mismo, le resultaba inaceptable la concepción modularista simple, análoga a la arquitectura de los ordenadores. La inspiración de Vygotsky configuraba las bases de su aproximación, correctamente en mi opinión.

Casi una década después, fue nuevamente decisivo en mi trayectoria al apoyar mi migración de la filosofía de la ciencia a la psicología básica, a la psicología del lenguaje y el pensamiento en particular. Como escribió en su memoria para la cátedra, "cada vez será más difícil encontrar profesores de psicología del pensamiento y el lenguaje, porque hacen falta conocimientos de lógica y de lingüística, además de psicología”. Pensó que podía ser uno de ellos y me animó a dar el paso, y le estoy muy agradecido por ello, aunque no llegó a verlo. Me gusta pensar que aprobaría las cosas en que he estado haciendo. Gracias por todo, Ángel.

\subsection{Un Everest en los desafíos del desarrollo infantil}

Daniel Valdez. Doctor en Psicología por la UAM. Psicólogo clínico y educativo. Docente

Ángel Rivière consideraba al autismo como un Everest en los desafíos del desarrollo infantil. La montaña más alta, la más difícil de escalar. El que sea capaz de escalar, decía Ángel, verá cosas diferentes desde allí. La pasión por el autismo era pasión por las personas y el desarrollo humano. Hay llaves invisibles que nos abren puertas para comprender mejor la ontogenésis, para vislumbrar las claves del desarrollo simbólico, para descifrar el complejo entramado que ofrece el desarrollo de la inteligencia social, las competencias mentalistas y el sentido de la actividad. Ángel fue maestro en el aprendizaje de esas llaves. Él las vio e hizo lo imposible para hacerlas visibles a los ojos de los docentes, de los terapeutas y de las familias. El ascenso del Everest lo comprometía cada día más con la investigación rigurosa; la formulación de nuevas preguntas; la imaginación de nuevas pruebas para indagar lo que nos parecía prácticamente imposible de investigar; la creación de nuevos dispositivos de evaluación, diagnóstico y tratamiento del autismo y del síndrome de Asperger. Se adelantó a muchos manuales con su propuesta dimensional del Inventario de Espectro Autista (IDEA). Un instrumento fundamental no solo para señalar un nivel de alteración cualitativo, sino también para brindar orientación en la búsqueda de herramientas adecuadas para la intervención psicológica y educativa. Inspirados en esos trabajos diseñamos con Ángel las pruebas para evaluar competencias mentalistas sutiles (comprensión emocional, relevancia, ironías, metáforas) que dieron forma a la investigación de mi 
tesis doctoral en la UAM. Pocos saben, hasta hoy, que algunas de esas pruebas fueron fruto de largas charlas en las madrugadas de Buenos Aires, entre chistes, poesías, muchas risas y debates interminables, a veces acompañados de Malbec y en un duelo apasionante: escuchar una y otra vez la misma canción, una vez cantada por Marian Anderson (su preferida) y otra cantada por Jessye Norman (la mía). “¡Cómo te equivocas, Dani!", me decía. "Marian es la mejor, es la maestra”. Ángel ha sido nuestro amigo y maestro. Ojalá en nuestras prácticas cotidianas alguna nota, alguna armonía, algún silencio, lo sigan evocando con justicia. Considero que hasta el día de hoy no se valora en toda su dimensión cómo el trabajo lúcido, profundo y generoso de Rivière cambió la perspectiva del autismo en Latinoamérica.

El autismo, decía Ángel, nos produce un efecto que es capitalmente importante; el autismo nos extraña del desarrollo típico... y sin extrañeza no hay conocimiento.

\subsection{Como el diamante químicamente puro}

María Luisa Ramón-Laca. Profesional de apoyo en otras discapacidades del desarrollo

Ángel Rivière el amigo. La figura de Ángel Rivière como científico, como insigne profesor de Psicología Cognitiva es de todos conocida. Yo hoy quiero resaltar su talla como ser humano.

Tuve la suerte y el honor de haber mantenido con él una relación de amistad sincera y profunda. Fui compañera suya de carrera y la diferencia de edad (yo era veinte años mayor que él) nunca fue obstáculo para que de nuestra relación surgiera esa rica amistad que, día a día, hora a hora, durante los cinco años de universidad, se fuera forjando y durara a lo largo de sus cincuenta años de edad. Siempre que podíamos nos sentábamos juntos en clase.

Tenía una personalidad arrolladora y una gracia especial en su chispeante conversación. En aquellos años, comienzo de los setenta, la universidad vivía una etapa convulsa y bastante conflictiva, que puso de relieve el compromiso y la valiente actitud de Ángel, siempre dispuesto a ayudar y defender a sus compañeros de clase.

Recuerdo un día en que Ángel había protagonizado una de estas acciones generosas y valientes en favor de un compañero y estábamos comentando el hecho en la cafetería de la facultad. Se hablaba de la generosidad de Ángel, de la coherencia entre sus valores, sus ideas y su forma de reacción. Una compañera nuestra dijo: "Es que Ángel es como el diamante químicamente puro”...

\subsection{Una influencia}

María Jesús Sanz. Profesional de apoyo en otras discapacidades del desarrollo

Tuve la enorme suerte de poder tenerlo como profesor en un seminario organizado en la Escuela en la que estudiaba. En el año 82. Sus conocimientos y su forma de transmitirlos influyeron en mi vida profesional. 


\subsection{Sitios tan queridos de nuestra memoria}

Karina Solcoff. Doctora en Psicología por la UAM. Psicóloga clínica y docente universitaria

Conocí a Ángel Rivière en Buenos Aires. El recuerdo me lleva a la esquina de Callao y Santa Fe, el tiempo detenido en la risa, el tiempo detenido. Ángel cruzando despacio la avenida, ignorando las bocinas de los coches, saliendo con nosotros de la pizzería "Los Inmortales", transitando quién sabe qué ideas o qué pensamientos en la noche porteña. El frío del invierno obligando a levantarse el cuello del abrigo, las manos en los bolsillos, Ángel apurando el paso... Mi proyecto de tesis comenzó allí, enhebrando en el aire sus palabras, sus escritos, sus clases, sus explicaciones, su mirada sobre la memoria autobiográfica, sobre el desarrollo subjetivo, la profundidad de sus observaciones.

Recuerdo el sentimiento de escuchar por primera vez a Ángel Rivière, en una jornada sobre autismo en la universidad, junto a alumnos, colegas, familias de personas con autismo. Para tantos niños, niñas y jóvenes con autismo el futuro no fue el mismo a partir de esos encuentros con Ángel. Hoy advertimos lo afortunados que fuimos quienes tuvimos la oportunidad de escucharlo, de estar allí, en el momento justo y en el lugar indicado.

"Hay algo común a ustedes y a mí, en este momento, que es el aire que respiramos, que está vibrando mientras yo hablo... Cuando hacemos lenguaje estamos editando como energía física nuestras mentes, estamos convirtiendo la energía física en estados de la mente”, decía Ángel en Buenos Aires allá por el año 1999. No sé si en ese entonces éramos conscientes de lo que estaba sucediendo en nuestras mentes a medida que las palabras de Ángel vibraban en el aire compartido del auditorio de la universidad. Como un big bang psicológico, para muchos de nosotros sería el inicio de algo que cambiaría nuestros proyectos profesionales y nuestros mundos mentales para siempre.

Uno vuelve siempre a los viejos sitios donde amó la vida, y entonces comprende cómo están de ausentes las cosas queridas, dice una canción que solíamos escuchar con Ángel.

Cuánto seguimos echando de menos, veinte años después, las conversaciones, las risas, los diálogos entrañables con nuestro maestro y amigo Ángel, sitios tan queridos de nuestra memoria.

\subsection{Balada para un loco}

Miguel Ángel Verdugo. Profesor universitario

El polaco Goyeneche, cantante argentino de tangos, con su inolvidable, expresiva y grave voz cantando Balada para un loco fue uno de los momentos más importantes que vienen a mi memoria del tiempo pasado juntos en 1993 en Buenos Aires. Ángel, 
como el famoso tanguero, transmitía emociones con su voz y en su habitual manera de ser, ya sea como docente, como investigador, como colega o como amigo.

Las emociones se alojan en la mente de las personas, generan sentimientos, y se mantienen durante mucho tiempo más allá de las meras palabras, aunque estas se expresen con la máxima precisión. Por eso, las aportaciones científicas de Ángel al conocimiento psicológico y a la intervención y apoyo con niños y adultos con discapacidades significativas permanecen en todos los que tuvimos la oportunidad de compartir con él actividades y momentos vitales relevantes. Sus palabras no solo hacen pensar y permiten aprender y sumirse en la profundidad de conocimientos transmitidos, sino que también vienen envueltas en un compromiso personal y adornadas con una atractiva presentación.

Yo tuve la suerte de tenerlo como profesor en la Universidad Autónoma de Madrid (UAM) y después como colega y amigo, disfrutando de su saber y de su compañía en muchas actividades académicas, a las que siempre acudía, y que constituyeron el germen del nacimiento del Instituto Universitario de Integración en la Comunidad de la Universidad de Salamanca, iniciativa que intentamos fuera paralela en la UAM. Se nos quedó pendiente una estancia querida y prometida de investigación en el INICO de la Universidad de Salamanca, pero su entrañable recuerdo para muchos de nosotros hace que esa estancia sea permanente en nuestra mente. Por ello, lo recordamos en todas las Jornadas Científicas que organizamos con una sesión especial.

Un brindis con buen vino tinto de la Ribera de Duero por Ángel, y aquí seguimos queriéndole "piantaos, piantaos”, esperando encontrarle de nuevo.

\subsection{Fue un privilegio tratarte}

Javier Muñoz Bravo. Familiar de persona con TEA

Me cuesta encontrar palabras para recordar a Ángel Rivière y es un poco paradójico ya que mi primer contacto personal con él fue en la Facultad de Psicología de la UAM cuando yo era alumno en su clase de psicología del lenguaje.

No fue este sin embargo nuestro primer “encuentro". Ángel hizo el diagnóstico de autismo de mi hermano cuando mi hermano ya tenía 12 años y mis padres, especialmente mi madre, habían estado peregrinando de especialista en especialista sin que nadie les arrojase ninguna luz. Aún conservo ese informe y recuerdo la ilusión de Ángel cuando se lo enseñé muchos años después de que lo hubiera escrito. Leer el informe le hizo revivir sus comienzos profesionales y el reto que suponía iniciarse en el mundo del autismo.

Recuerdo su apoyo y su confianza. Ángel me ayudó a iniciar mi carrera profesional permitiéndome colaborar con él y pasándome los primeros casos.

Recuerdo su amabilidad y su incapacidad para decir que no cuando le pedías ayuda o consejo.

Recuerdo su brillantez abrumadora y cuánto aprendías de él.

Recuerdo el hueco inmenso que dejó. 
Recuerdo mis lágrimas en el crematorio de La Almudena cuando tantos fuimos a despedirnos y recuerdo, como allí se dijo, que pese al dolor por su pérdida es obligado estar agradecidos por haber tenido la oportunidad de conocerle.

Así pues, gracias, Ángel, fue un privilegio tratarte.

\subsection{Un camino apasionante}

Aitor Larraceleta. Profesional de apoyo especializado en personas con TEA

Las palabras “Ángel Rivière” trascienden la identificación de una persona, se convierten en aquello que esa persona simboliza. En mi caso, un camino apasionante en un ámbito, el del autismo, en el que me introdujo a través de sus lecturas y conferencias.

En su momento, me planteé cómo le podía rendir mi pequeño homenaje y, finalmente, se me ocurrió, junto varios amigos, escribirle una canción inspirada en el reflejo que su persona me proyectaba (¿qué es lo que él diría?) cuando compartía recreo con algunos de los alumnos con autismo con los que conviví muchos años. De esa experiencia, surgió la letra de esta canción llamada... Rivière.

"Recubren los abismos de azul multicolor".

(Ver video): https://youtu.be/kbTPANN-x6o

\subsection{Sabiduría, bumildad y bondad}

Carmen Gallardo. Profesional de apoyo especializada en personas con TEA

Ángel Rivière, le leí mucho, le escuché varias veces, alguna vez le tuve cerca, en el centro Gaspar Hauser donde trabajé 29 años siguiendo sus directrices en nuestro equipo. No solo destacar su sabiduría, también su humildad y su bondad, sin olvidar su belleza de perfil griego. Para siempre.

\subsection{No podías llevar otro nombre}

Mayka Morueco. Asesora de viajes

Querido Ángel..., no podías llevar otro nombre, Ángel para tu familia, tus amigos y siempre en nuestro corazón, con tu humor, tan agudo e inteligente, que no sólo dejaba una estela de alegría por donde pasabas, sino que tenías el ojo clínico tan certero, que ibas más allá del diagnóstico precoz, eras un visionario de la vida, de tus amigos, sabías bien de aquellos diamantes en bruto que tú pulías como una pieza única, irrepetible... y así ha sido, Ángel, cada pieza, modelada con tu hábil destreza, ha sido y, por muchos tropiezos que la ignorancia pone en el camino a los auténticos, sigue siendo única, mejorando y apasionando a cada uno que compartía la enseñanza y la vida 
contigo. Sin ir más lejos, mi hermana, Maribel Morueco, otra estela en el Universo Eterno e Infinito del Conocimiento: gracias a ti, te ha correspondido ella, haciendo lo mejor de su profesión, formando a otros profesionales y mejorando con esa libertad de tu mirada a quienes no lo eran, y los que han tenido la suerte de aprender contigo, yendo más lejos, siempre mirando al horizonte, como lo hacías tú y tu eterna sonrisa.

Gracias por dejarme esa herencia en mi hermana. Te asombraría su legado, haciendo felices a familias enteras gracias a su buen hacer. Desde alguna de las estrellas que más brillan, ahí estás tú, viéndolo, orgulloso y tranquilo, con esa tranquilidad aparente que sólo tienen los genios, mientras su cabecita está en mil análisis a la vez, sin esfuerzo alguno.

Gracias por nuestras risas, cuando la conversación era tan interesante, había tanto que contar, tu amor por Mallorca, que hasta nos saltamos la salida que nos llevaba al aeropuerto, porque soñabas con el Azul de esta isla y te imaginabas descansando en su silencio contemplativo, frente al mar, inmensamente azul. Siempre estarás en nuestro Corazón y ha sido un privilegio poder conocerte a ti y a tu preciosa familia.

\subsection{7. ¿Qué me diría una persona con autismo?}

\section{Daniel Comin. Persona con TEA}

Fui diagnosticado de autismo severo con 2 años de edad. Toda mi vida la he pasado de terapeuta en terapeuta y tiro porque me toca. De colegio en colegio y tiro porque me toca. De conocer personas y verlas desaparecer una y otra vez, aquí no tiro porque me toca, aquí tener amigos ni siquiera puedo escoger para ver si me toca, cuanto más creces más invisible eres.

Este relato en reconocimiento a Ángel Rivière es para contar que es ahora con 17 años me intereso por mi autismo, porque hace unos meses me realizaron pruebas para actualizar mi dictamen escolar y cuando me lo dieron me llamó la atención el nombre de Ángel. ¿Quién es este señor que aparece aquí? ¿Por qué lo ponen? No sé quién es.

Mi madre me sentó y me explicó toda su labor y que a día de hoy las pruebas que me hicieron eran por una escala creada por él que mide muchas de las características de personas con trastornos del espectro autista. La escala y el dictamen dicen que ahora no tengo autismo severo, pues tantos años de tiros porque me tocaban estoy en un grado leve, tanto es así que ahora soy invisible, no soy como los demás pero soy también diferente a otros chicos con autismo de los que he ido conociendo.

Leí un texto de Ángel que dice: ¿Qué me diría una persona con autismo?

Todas son importantes, pero para mí es:

1. Ayúdame a comprender mi entorno. Organiza mi mundo y facilítame que anticipe lo que va a suceder. Dame orden, estructura y no caos.

Y añadiría solo una. Ayúdame a defenderme incluso de las personas que dicen amarme pero no lo sienten. 
ÁNGEL RIVIÈRE EN EL CORAZÓN Y EN LA MEMORIA

DE LA PSICOLOGÍA ESPAÑOLA Y DEL AUTISMO

M. Á. VERDUGO, R. CANAL, M. ${ }^{a}$ SOTILlO, M. MORUECO Y J. TAMARIT

\subsection{Angel: referente profesional y bumano}

José Luis Cabarcos. Profesional de apoyo especializado en personas con TEA

Es muy emocionante para mí recordar a una persona tan querida como Ángel Rivière al que tuve la suerte de conocer en mis primeros años como profesional del Centro TAURE y de la Asociación PAUTA. Una época inolvidable en la que se crearon nuevos recursos clínicos y educativos para las personas con autismo en Madrid. Ángel dinamizó de forma excepcional nuestro campo de trabajo, desarrollando e impulsando la comunicación entre la universidad, los profesionales y las asociaciones de familiares. Fue asimismo un extraordinario comunicador. Asistir a sus conferencias era un auténtico placer: poseía un magnetismo especial, jugaba con el lenguaje y sus palabras siempre estaban llenas de pasión, rigor científico e implicaciones prácticas a partes iguales. Era además muy creativo. Te hacía ver los problemas desde otros ángulos y tenía una capacidad única para hacer que conceptos psicológicos complejos e invisibles se volviesen claros y comprensibles.

Me gustaría recordar algunas de sus frases que reflejan su manera de entender el autismo y que siguen plenamente vigentes en la actualidad:

- Para tratar el autismo adecuadamente tenemos que basarnos en los modelos de explicación psicológica. "Solo entendiendo cómo funciona la mente de las personas con autismo podremos desarrollar intervenciones eficaces".

- Las explicaciones psicológicas son complementarias. "Todas tienen parte de razón y puntos en común. Lo que está alterado es un racimo de funciones críticas de humanización o universales de la especie muy fuertemente interrelacionadas".

- Los datos neurobiológicos son fundamentales pero tienen que estar guiados por el conocimiento psicológico del trastorno. "Las hipótesis psicológicas son la garantía de seriedad de las hipótesis neurobiológicas".

- Es muy importante estudiar el desarrollo típico para entender mejor el autismo y comprender el autismo para conocer mejor el desarrollo típico. "Tenemos que tener siempre un ojo puesto en el desarrollo típico y otro puesto en la persona con autismo para poder entenderla y tratarla mejor".

- El desafío de la investigación psicológica consiste en descubrir la génesis y evolución de las habilidades que están alteradas. "Hay que estudiar pasito a pasito el desarrollo evolutivo de habilidades como las mentalistas o las ejecutivas para poder trabajarlas con personas que se sitúan en diferentes niveles del espectro".

- La clave de la intervención está en la educación. "La respuesta educativa no la establece el diagnóstico sino el niño. Ningún dogma nos sirve para entender educativamente a las personas con autismo".

- Es necesario combatir los mitos clásicos del autismo. "Los mitos tienen mucha fuerza pero se desmontan con conocimiento científico".

- Conviene ser cauto y precavido ante las terapias sin evidencia fruto de las modas. "El autismo solo se mejora en la interacción social porque ahí se construye desarrollo". 
- Es esencial conocer a la persona con autismo, tenerla en cuenta, observando sus haberes por encima de los déficits. "Solo conociendo a las personas con autismo desde dentro podemos ayudarles como profesionales desde fuera".

- El apoyo a las familias es absolutamente capital. "Necesitan ayuda desde el principio porque el autismo es culpógeno siempre. Hay que aprender a convivir emocionalmente con el hijo con autismo".

Ángel fue un adelantado a su tiempo. Se anticipó en décadas a la concepción dimensional del DSM-5 desarrollando el Inventario de Espectro Autista (IDEA). Intuyó que los procesos que conducen al autismo comienzan en la fase de neurogénesis entre el primer y segundo trimestre de vida intrauterina. Él ya hacía entonces "práctica basada en la evidencia" tal y como se define actualmente e insistía en la importancia del trato (centrado en la persona y en su bienestar) y no sólo en la del tratamiento (los aspectos técnicos de la intervención) desde una visión global de la salud. Recuerdo que organizó las "Primeras jornadas sobre investigación en trastornos del desarrollo: cerebro y autismo" de APNA porque era consciente de la importancia de la neuropsicología. ¡Cuánto habría disfrutado con los hallazgos de la investigación en neurociencias de estos últimos años! Aquel día después de escucharlo supe que quería formarme como neuropsicólogo.

Conocer a Ángel cambió mi visión sobre los valores de mi trabajo de manera profunda porque no sólo fue un referente como psicólogo, sino también como persona. Creo que no se puede entender su actividad profesional desvinculada de su dimensión humana: era honrado, humilde, generoso y estaba totalmente entregado a sus alumnos, a las personas con autismo y a sus familias. Tristemente se fue demasiado pronto. Un ciego accidente de la biología (como diría él) nos lo arrebató de una forma cruel. Pero el ejemplo de su vida permanece y es un horizonte a seguir. Cuando me preparo cada mañana antes de comenzar mi trabajo diario y miro durante un instante su maravilloso decálogo "Qué nos pediría un autista”, que cuelga de la pared de mi despacho, siento una mezcla de nostalgia y optimismo al pensar que, de alguna manera, Ángel sigue vivo en el interior de quienes tuvimos el privilegio de conocerlo.

\subsection{Hablando de Ángeles}

Ricardo Baquero. Profesor universitario

"Los ángeles $[\ldots]$ deben recurrir a este razonamiento discursivo [ ...], cuando intentan predecir el futuro, lo que solo pueden hacer por inferencias de causas a efectos, $\mathrm{o}$ adivinar los pensamientos secretos de los humanos, lo que nuevamente requiere inferencias indirectas de signos corporales externos. (Solo Dios conoce de inmediato el futuro y los pensamientos y deseos más íntimos de la razón y la voluntad humanas)". Lorraine Daston. Intelligences. Angelic, Animal, Human.

El sugestivo escrito de Daston compara las inevitablemente antropomórficas especulaciones de los teólogos sobre los atributos psicológicos de los ángeles -en sus 
variadas jerarquías y tipos- con aquellas presentes en los intentos por comprender la inteligencia animal, en la primera mitad del siglo XIX. Los ángeles parecen ser literalmente "incorpóreos" -haga el lector el enorme esfuerzo por suspender su pensamiento metafórico-, pero reconocen individuos a los que hacen llegar mensajes divinos. Por tanto, distinguen, comunican, e incluso pueden sentir alegría, pero no tristeza. Nuestro entrañable Ángel Rivière padeció y disfrutó, intensamente, como vivió, claro, el desasosiego y las modestas alegrías de imaginar y comprender lo humano mismo, espejado ilusoriamente en los objetos -con mente o sin ella-, los animales, los ángeles o el espejo roto de la normalidad, que nos devuelve cada vez más diversidad, más humanidad diversa, tan angelical como animada. Y el pensamiento tipológico y jerárquico se fatiga y nuestro Ângel, ahora, como un sensible teólogo, intenta juntar las piezas de esta diversidad, que desvela con su urgencia cuando sospechamos o constatamos un sufrimiento. Sufrimientos mutuos que se vuelven más pronunciados, aún, por nuestra imposibilidad de pronunciar sus sentidos, o insinuar los gestos de un mundo común.

El arte autista, solo un ejemplo, nos obliga a imaginar, sigo a Rivière, la posibilidad de expresar emociones e intuir privilegiadamente las formas de una manera algo despojada del ruido de nuestra mundana cultura. Otro arte que no aspira a comunicar intencionalmente esa emoción, como aquel jerarquizado y tal vez, al fin, limitado. Se trata tal vez de "un arte del silencio", pronuncia Ángel. Al fin, las palabras que profanan la lógica cruel del pensamiento del déficit, la ausencia y la carencia, apostándolo todo a la ruidosa vitalidad de una ontogénesis impredecible. La prueba de que algo de lo angelical es verosímil es que seguimos, incorpóreamente, dialogando largamente con él, mientras su pequeño Pablo sopla mecheros con fuegos imaginarios.

\subsection{Un recuerdo muy especial a su sensibilidad y ternura}

Isabel Rivière. Orientadora escolar. Hermana de Ángel

En nuestro CV debería figurar: Fui alumna del MAESTRO Ángel Rivière, esto sin duda da prestigio a nuestra formación.

Ángel fue profesor mío en la asignatura de filosofía de COU, también fue quien me orientó profesionalmente. Durante la carrera no tuve la suerte de tenerle en las asignaturas que entonces impartía, Historia de la Psicología y Pensamiento y Lenguaje, porque cambió de la Universidad Complutense a la Autónoma, pero muy entrados los años 70 tuve la suerte de participar con él en un seminario semanal sobre autismo. Eran los primeros momentos en que empezó su especialización como asesor de APNA (Asociación de Padres de Niños Autistas) y fue en el entorno de ese seminario donde pusimos en marcha el Primer Congreso Internacional sobre autismo.

La especialización de Ángel en autismo me dio paso para sustituirle en el puesto que ocupaba como psicólogo escolar en el colegio de nuestros padres, porque Ángel para mí antes, mucho antes que mi maestro, fue mi hermano.

Ángel era el mayor de una familia de ocho hermanos, de la cual yo soy la séptima. Nuestros padres siempre estuvieron muy atareados con el colegio, por lo que en casa 
estábamos al cuidado de nuestra abuela, quien vino a ser nuestra segunda madre poniendo en Ángel todo su empeño, como si esforzándose en su buena educación, todos los demás acabaríamos haciendo lo que él marcaba, así poco a poco fue creciendo su "poder" en el grupo y como primogénito se fue convirtiendo en una persona responsable y autoexigente.

Ángel fue un estudiante de los años 60, en pleno fervor de revueltas políticas, de manifestaciones, de asambleas universitarias a las que Ángel como delegado de curso no faltaba.

Pensar en Ángel me evoca olor a cafés de sobremesa, largas conversaciones sobre cualquier tema en las que a veces jugaba a defender a muerte una postura hoy, que podría en otro día ser la contraria por el solo divertimento de generar pensamiento crítico. Pensar en Ángel es pensar en el pueblo, en su disfrute de paseos por el Duratón, en su casa de Ahusín. Ángel y la guitarra, la familia. Es también el mar, veraneos en la playa, con los juegos de cartas a los que jugaba siempre con talante de ganador.

Aprendí de Ángel muchas cosas, aprendí a mirar todas las diferentes perspectivas desde las que se debe analizar un problema, a utilizar la empatía en el trabajo con familias, el arte de saber escuchar y de observar, aprendí a dar importancia a la formación y especialización profesional, a tantas otras cosas.

Pero, sobre todo tengo que dedicar un recuerdo muy especial a su sensibilidad y ternura, a su trato y gran atractivo personal. Todo el que haya conocido a Ángel compartirá conmigo este sentimiento.

Doy gracias a la vida por haber tenido la suerte durante 40 años de disfrutarle como hermano.

\subsection{Siempre te recordaremos}

Antonia Massanet. Exjefe de Estudios del CEE Gaspar Hauser de Mallorca

Ángel, ya destacabas como un prestigioso psicólogo y especialista en TEA en la década de los 80, cuando estudiaba Pedagogía Terapéutica en la UIB (Universidad Islas Baleares). Más tarde, te pude conocer gracias a los Congresos que se iban celebrando en diferentes ciudades. También tuvimos el gran honor de que impartiste varios cursos en nuestro propio CEE Gaspar Hauser y pudiste conocer a nuestro alumnado TEA. Me impactó tu sabiduría acerca del diagnóstico y pronostico del alumnado y tu fuerte calidad humana. Me ayudaron mucho tus enseñanzas, para diseñar programas individuales: objetivos, actividades, refuerzos... y Estructura del ambiente... contingencias, dirigido hacia Escuela inclusiva... Has sido y eres un potente referente en todas las enseñanzas-aprendizajes.

Gracias por todas tus orientaciones, valoraciones, metas e ilusiones y haber podido aprender tanto de tu bibliografía.

¡Siempre te recordaremos!!!!

Hasta siempre, Ángel. 
ÁNGEL RIVIÈRE EN EL CORAZÓN Y EN LA MEMORIA

DE LA PSICOLOGÍA ESPAÑOLA Y DEL AUTISMO

M. Á. VERdUGO, R. CANAL, M. ${ }^{a}$ SOTILlO, M. MORUECO Y J. TAMARIT

\subsection{Era imposible escucharle y no sentirse fascinada}

María Llorente. Profesional de apoyo especializada en personas con TEA

Mi deuda con Ángel Rivière es inmensa. Muchas de las cosas que más feliz me hacen se las debo directa o indirectamente a Ángel. Me matriculé en la Facultad de Psicología convencida de que mi futuro profesional estaría vinculado a las prisiones, pero solo necesité escuchar una clase de Ángel para sentirme cautivada e intrigada por el autismo. Algo que después supe que les pasaba a muchos de sus alumnos. Era imposible escucharle y no sentirse fascinada con todo lo que contaba sobre las personas con TEA y sobre la alteración de los procesos psicológicos que son fundamentales para el desarrollo socio-comunicativo durante los primeros años de vida; alteración que, según sus palabras, cubría al niño con sus blancos copos de silencio. Desde entonces he estado vinculada a este campo y desde entonces disfruto cada día con mi trabajo. Gracias, Ángel.

Pronto comenzó a derivarme algunos niños para que me encargase de su intervención, siempre bajo su tutela, orientación y supervisión. Han pasado más de 20 años y sigo en contacto con muchas de esas primeras familias y con sus hijos que ya son adultos jóvenes. Con todos ellos he aprendido y sigo aprendiendo. A su lado me he emocionado y me sigo emocionando y junto a ellos he pasado momentos inolvidables.

Gracias, Ángel, por llenar mi vida de personas tan maravillosas.

Sus explicaciones, artículos y clases me han permitido comprender este trastorno del neurodesarrollo de una manera que estoy segura que no hubiese podido conseguir sin ellos. La visión de Ángel del autismo como un trastorno dimensional y con una enorme variabilidad intersujetos (visión que quedó maravillosamente recogida en el Inventario IDEA) me ha permitido comprender con mayor facilidad la visión actual del autismo. Ángel, hace ya más de 20 años y anticipándose a su tiempo, empezó a preparar a sus alumnos para que fuésemos capaces de adoptar un enfoque del autismo lejos de categorías cerradas y rígidas. Gracias, Ángel, por esas explicaciones.

En la esfera de lo personal, Angel me presentó a otras personas vinculadas al mundo del autismo. Inicialmente perfectos desconocidos y, hoy en día, compañeros de trabajo además de amigos imprescindibles en mi vida. De nuevo gracias, Ángel.

\subsection{Como una lluvia suave}

Ana González. Profesional de apoyo especializada en personas con TEA

Ángel Rivière era quizás una de esas personas que tienen el talento y la habilidad para enseñarte a amar lo que ellos aman. Como una lluvia suave, clase tras clase, nos fue empapando de su ilusión, de sus ganas por comprender (y no sólo describir) a las personas con autismo, de su mirada científica y poética al mismo tiempo y de esa forma de ser tan suya: generosa, apasionada, cercana y brillante. 


\subsection{4. Ángel Rivière. Amistad y admiración}

José Javier (Checho) Lasa. Librero jubilado

Conocí a Ángel a finales de 1970 o principios de 1971. Venía frecuentemente con Inés a mi casa de recién casado con Elena, compañera de ambos en Comunes de la Complutense y por quien los había conocido.

Charlábamos animadamente hasta altas horas de la noche, nos despedíamos y poco después sonaba el teléfono o el timbre del portal: Ángel había olvidado las gafas, las llaves de su casa o del coche. Algo que no podía esperar al día siguiente. Sus despistes de siempre, que comentábamos benévolos y divertidos.

Luego, en mi primer curso de la carrera de Psicología, fui alumno suyo en lo que para él era el primer año como docente universitario de su larga y fecunda carrera.

Más tarde, por haber fallecido recientemente el padre de Inés, fui padrino de su boda, lo que me hacía sentir, tal vez un poco tontamente, con cierta ascendencia.

Él me animó a llevar adelante el proyecto de librería a la que dediqué tantos años y que se inauguró, precisamente, antes de la apertura al público, como un stand en el primer Congreso Internacional sobre Autismo, que organizó APNA, en el que puso tanta ilusión y esfuerzo y que constituye, sin duda, un hito en el desarrollo de los estudios y la atención al autismo en España.

En Ángel yo admiraba su interés por el estudio del autismo, pero sobre todo su proximidad y dedicación a las familias de niños con TEA.

Admiraba su entusiasmo por la psicología teórica, pero también por la filosofía, la literatura o la acción política.

Admiraba su dedicación a la tarea universitaria y su propósito de acercarse y rodearse siempre de los mejores colaboradores.

Éramos amigos y admiraba a Ángel. La amistad perdura de forma extraña y tranquila, tras su ausencia y el paso del tiempo. La admiración ¿̇no será un componente, en grado diverso, de toda amistad?

\subsection{Un Ángel inspirador}

\section{Ricardo Canal. Profesor universitario}

Ángel Rivière fue ejemplo de cómo investigar para todos nosotros. En el último cuarto del siglo XX la ciencia española mostraba poco interés por el autismo. Desde finales de los 70 y desde el 2000 hasta hoy Ángel representa en España el despertar a una forma nueva de hacer ciencia en psicología, ciencia por y para las personas, comprometida, en primer lugar, con quienes tienen autismo, o un trastorno del desarrollo, bebés, niños, jóvenes, adultos; en segundo lugar, con quienes viven con ellos, madres, padres, hermanos, amigos; y en tercer lugar, con profesionales de muchos ámbitos, de la psicología, la educación, la salud, etc. Vivía entre la ciencia y la conciencia. Cuando te escuchaba solo te escuchaba a ti, reconocía tu esfuerzo, dejaba que compartieras tu 
ilusión con él y se dejaba seducir por tu visión. Le importaba saber, quería explicar y era solidario con todos. Se daba a cada uno en cada momento. Se concentraba tanto que podía perder la noción de todo lo demás. Recuerdo una noche de finales del 99, dentro de su coche, en la Autónoma frente a Psicología, debatiendo sobre atención conjunta. No quiero pensar lo que pudo imaginar el vigilante del campus cuando a las 23:30 se acercó al coche. Le vio y dijo "Ah, es usted”.

Abría su mente, su corazón y su propia casa a todo el mundo. En términos universitarios alguien diría que lo que hizo fue combinar magistralmente la psicología académica con la psicología aplicada. Pero hizo algo más que eso, porque sus formas de escribir, de comunicar con palabras y silencios, y de plantear los temas con imaginación y un punto de erudición nos inspiraron. Demostraban un esfuerzo continuado y original por encontrar explicaciones científicas, declarando la voluntad de aportar soluciones prácticas para una condición muy difícil de explicar aún hoy, a la que él se acercaba con los brazos abiertos y la mente llena de preguntas y proyectos.

Al evocar su memoria estos días no puedo evitar que surja la emoción y algo se empañen mis ojos. Durante algún tiempo después del 2000 creí haberme quedado solo. Ahora sé que no, que en estos 20 años me ha acompañado su recuerdo, el cual he podido compartir con muchas personas. También he de decir que la gran mayoría de las decisiones importantes que he tomado en mi vida profesional están matizadas por su memoria y sus enseñanzas.

\subsection{Que en el día nuevo sea tu cielo el que nos acompañe}

Arabella Villalobos. Profesora jubilada de la Universidad de Educación a Distancia (UNED) y psicóloga clínica

Han pasado 20 años y las palabras se tornan pobres e insuficientes para expresar lo que significó, y aún significa, la presencia de Ángel en mi vida.

Fue mi amigo y maestro, pero no solo eso pues su casa, junto a Inés, Mario, Lucía, Inesita y Pablo, durante muchos años fue mi hogar.

Recuerdo su bondad y tolerancia cuando Inés y yo nos reíamos comentando las erróneas expresiones verbales de algunos presentadores de TVE o los versos de poetas insufribles, cómo nos miraba y decía "no seáis así”, porque Ángel nunca pudo señalar sin compasión los errores de los demás.

Otras veces le contaba las veleidades sentimentales que me abrumaban y de inmediato se deshacían debido a su manera de escuchar haciendo que el otro se sintiera importante y devolviendo siempre consuelo y comprensión.

De su mano comencé a trabajar en Taure. A veces, en el quehacer cotidiano con los niños, la naturaleza enigmática del autismo nos desbordaba, pero él insistía en que se precisaba más teoría para mejorar la práctica e inició un Seminario Permanente en el que estudiábamos los nuevos enfoques conceptuales y las estrategias de tratamiento que de estos se derivaban. Muchos otros han dado sobrada cuenta de lo que ha significado la obra de Ángel tanto a nivel teórico como aplicado en la historia del autismo. Por 
mi parte, abandoné ese campo para dedicarme a la intervención en adultos con problemas emocionales, pero aún releo sus textos, que me siguen enseñando a escribir. Recuerdo su empeño en la importancia de cuidar la comunicación escrita, capacidad infrecuente en los psicólogos clínicos, que defendía como una obligación. No solo como escritor, su elocuencia y precisión al hablar era tal que un día alguien que había acudido a escuchar una conferencia suya me comentó: "Ángel no habla, hipnotiza”, acertada manera de señalar la impronta que en todos sus oyentes dejó.

Queridísimo Ángel, este objeto con mente ahora y siempre te piensa y sabiendo que otros vendrán y cimentarán su trabajo y su camino en tu legado, vuelvo a los versos de Pedro Salinas, el poeta que tantas veces Inés nos recitó: "Y que en el día nuevo sea tu cielo el que nos acompañe”.

\subsection{De las mejores cosas que me han ocurrido}

Ricardo Rosas. Profesor universitario

Conocí primero al autor. A través de su magnífico escrito "La psicología de Vygotski: sobre la larga proyección de una corta biografía”. Me fascinó ese texto, lo puse de inmediato como bibliografía mínima en mis cursos y empecé a investigar quién podía haber escrito algo tan especial. Se notaba erudición, pero sobre todo pasión por el personaje. Y una comprensión profunda de su vida y obra. A los pocos meses, un cercano que conocía de mi fascinación por ese texto me contó que Ángel estaba en Chile, invitado por el Centro de Perfeccionamiento del Magisterio, junto a un grupo de la Universidad de Salamanca. Llamé de inmediato, y, para mi sorpresa, no me costó nada dar con él. Era viernes. Le propuse llevarlo a él y su grupo el día siguiente a Isla Negra, a la casa de Pablo Neruda. Aceptó de inmediato. Así comenzó una amistad que habría de durar muchos años.

Esta pequeña anécdota de cómo lo conocí creo que refleja muy bien un rasgo esencial de Ángel, su extrema generosidad. Volvió muchas veces a Chile, aceptaba cada invitación que le hacíamos, creo que muy a pesar de Inés, su querida esposa, que prefería que no viajase tanto. Gustaba de pasar el tiempo con los estudiantes de doctorado, con quienes podía mantener horas de conversación. Organizó grupos de investigación, que monitoreaba desde lejos.

Eran los tiempos en que desarrollaba su teoría de la suspensión semiótica como explicación del desarrollo de la Teoría de la Mente. Estábamos interesados conjuntamente en cómo este principio podía explicar cosas tan misteriosas como la metáfora o el sentido del humor (¡qué sentido del humor que tenía Ángel!). Le debo mucho. Lo extraño mucho. Con mi gran amigo Ricardo Baquero, que conocí gracias a Ángel, compartimos una especie de sentimiento de orfandad desde que se fue. Porque nos marcó su forma de pensar, de escribir y de actuar.

La intuición que me mostró de autor se vio multiplicada en la persona: su pasión por todo lo que emprendía era verdaderamente admirable y querible. Me alegra mucho haber contado con la amistad de un hombre tan especial.

Haberlo conocido es de las mejores cosas que me han ocurrido. 


\subsection{Todos merecíamos un maestro así}

Ruth Campos. Profesora universitaria

Una de mis suertes es haber sido alumna de Ángel Rivière.

Recuerdo que nos llamaba de usted; que dibujaba con ambas manos maravillosamente; que a veces suspendía la manga de su traje para crear un borrador; y que explicaba siempre como si confiara tanto en que le comprenderíamos que acabábamos entendiéndolo todo.

La humildad con la que presentaba sus modelos nos persuadía de que no cabía explicación alternativa. Los ilustraba con ejemplos de las conductas comunicativas de sus hijos y de las habilidades mentalistas de sus perros. Nos hablaba de las personas con autismo por sus nombres. Parecían un poco también de su familia, y las sentíamos escalar con él por el IDEA. Nos preguntaba por las emociones del conde-duque de Olivares y la Teoría de la mente era como cosa de magia, y él el mago que conocía todos los trucos.

Redescribía la pregunta más simple en una intervención extraordinaria, y contestaba todas las dudas como si le sobrara el tiempo.

Un día nos contó que detectó un problema de salud mental en una alumna, que en el examen escribió el Plan Nacional de Carreteras. Si nos lo hubiera explicado él, habríamos querido ser ingenieros de caminos.

Todos mereceríamos tener un maestro así.

Eso debió de ser lo que pensó mi madre, que me convenció para matricularme en la UAM (lejísimos), porque allí estaba ese profesor “tan listo y tan guapo" que le había dado clase, allá por el 76-77, en Somosaguas.

Como ya habrá prescrito, confieso también que, con el único propósito de impresionarla, colé en una clase suya de Lenguaje a mi pareja de entonces -y de ahora, se ve que funcionó-. Y que hice su optativa dos veces, un año de verdad y otro de polizona, para volver a escucharle (mientras cursaba el prácticum en su proyecto, y no hablaba nunca, no me fuera a pillar).

Aquel abril se apagó la luz. Tenía cerca a varios de sus amigos; su desolación me conmovió. Trataba de acompañarles, torpemente, con una pena -polizona tambiénque aún no se ha ido.

Durante un tiempo todos nos quedamos a oscuras. Pero enseguida fue evidente que había encendido cientos de candelas.

Veinte años después, su luz sigue brillando. Y seguirá alumbrándonos, y seguirá marcando el norte de tantos profesionales, familias, investigadores y docentes que tuvimos la suerte de conocerle, y que ahora tenemos el privilegio de presentárselo a los que llegan. 
ÁNGEL RIVIÈRE EN EL CORAZÓN Y EN LA MEMORIA

DE LA PSICOLOGÍA ESPAÑOLA Y DEL AUTISMO

M. Á. VERDUGO, R. CANAL, M. ${ }^{a}$ SOTILlO, M. MORUECO Y J. TAMARIT

\subsection{Recuerdos evanescentes}

María Sotillo. Profesora universitaria

Salamanca, octubre de 1986. Carmela: “María, ¿vienes con Marian y conmigo a la conferencia de un profesor de Madrid sobre desarrollo del lenguaje en niños con autismo?”. Fascinación es lo que queda en mi memoria, lástima no recordar lo escuchado y que los apuntes no hayan aguantado 7 mudanzas.

Ángel Rivière sabía crear impronta. No conozco a nadie que le haya conocido y no se haya sentido interpelado por sus conocimientos y personalidad. Fabuloso en las distancias cortas. Dan fe centenares de estudiantes y de asistentes a cursos, conferencias y congresos. Maestro en manejar la relevancia, conseguía que todos sintiéramos que hablaba para cada uno, respondiendo a nuestras expectativas.

Además, sabía manejar distancias más cortas. Recuerdo estudiantes suspensos en una revisión agradecidos por las empáticas explicaciones magistrales particularizadas, maestro también en desplegar su teoría de la mente.

Recuerdos evanescentes. La perdurabilidad de lo escrito permite que quienes no le conocieron le descubran y valoren. Para mí, releer Rivière siempre enriquece, no solo no ha perdido con el tiempo, es que era de antes de su tiempo, a la altura de otros del olimpo de los genios que hicieron cambiar modos de pensar y de hacer. En eso no tiene razón Pata Negra, pasó la vida, pero de tu obra, Ángel, sí queda la memoria.

Una memoria que no deberíamos perder: generoso con el conocimiento (aunque tuviera consecuencias), con el tiempo (aun a costa de no tener tiempo propio), con los compromisos (aunque no puntuaran). Una memoria que ojalá siga creando impronta, en larga proyección de una (demasiado) corta biografía, tu premonitoria frase.

Una memoria que restaure que tantas personas te echamos de menos, en cosas grandes y pequeñas. En aquellas comidas, en las que cogías la cuchara de manera peculiar o en cómo comías las naranjas, y escribías brillantes ideas en servilletas y trozos de mantel, que esos sí seguimos atesorando. Te extraño también en los debates, en una guía y acompañamiento, en las preguntas de la ciencia y en todas las demás.

Dos décadas han dado para muchas cosas. Algunas, me temo, no te hubieran gustado, han sido "peoras", se ha hecho "regulinchi" (en tu argot). Otras te habrían hecho "sobradamente feliz". Sé que te hubiera gustado saber que "la ciencia ha avanzado una barbaridad". Lo que hubieras disfrutado con todo lo que se sabe, no solo de autismo, y con las implicaciones que quizás no estamos sabiendo ver...

\subsection{La mirada perfecta}

M. Ángeles García. Profesora universitaria

Disfruté de las clases y seminarios de Ángel en tercero y cuarto de licenciatura. También me dio la oportunidad de participar como oyente en reuniones de su grupo de investigación sobre Teoría de la Mente. Poco después, me "regaló" asistir como 
observadora en alguna de sus sesiones clínicas; ¿Investigación?... ¿ Clínica?... “Tómate tu tiempo", me decía.

Comencé el doctorado uniéndome a su grupo de investigación. La admiración hacia él era incuestionable. Durante una sobremesa, sobre el mantel, armaba una nueva tesis con sentido pleno para el proyecto; sobre una servilleta, la llave del problema que te impedía avanzar. Mi primera intervención como ponente fue en un curso en el que, de su mano, participábamos varias compañeras. Imposible olvidar los días y noches de preparación, los nervios, las ganas de "no defraudar", de "responder a las expectativas”. Mi charla trataba sobre emoción en autismo, tema sobre el que versaría mi tesis doctoral. Eran sesiones de dos horas. Recuerdo los eternos minutos de tartamudeo, una media hora de bloqueo, el desorden de mis notas sobre aquella mesa, la desaparición de alguna transparencia... y la mirada de Ángel. Pero, más que con el estrepitoso fracaso de mi "puesta de largo", me quedo con su empeño por no dejarme sentir sola, por arroparme, por intentar sacarme alguna que otra risa durante la cena de clausura y sus palabras de camino al hotel, con su brazo rodeando mis hombros: "A la vuelta hablamos, pero habrá más de éstas. El siguiente curso creo que es en...”.

Desde aquellos inicios, las muestras de generosidad, de confianza en mí y mi trabajo, de cercanía, de afecto, de paciencia y también de sincera preocupación (y ocupación) por mí, bien en momentos personales objetivamente difíciles, o simplemente importantes para mí, fueron una constante en la relación con mi Maestro.

Hoy intento escribir con la perspectiva de “los 20 años después”. Continúa siendo difícil. En aquellos años tomé decisiones que marcaron mi vida profesional y personal, que me permitieron conocer gentes maravillosas y seguir unida a personas muy cercanas y queridas por él. Ángel sigue muy presente en mi vida no sólo a través de sus escritos, también de ellas. Quien mejor le conoce me regaló y dedicó, hace también 20 años, uno de sus últimos libros: "Hagas lo que hagas, él estará orgulloso", escribió. Y es que Ángel, cuando miraba, veía personas. Gracias, Inés. Gracias, Ángel.

\subsection{Qué suerte tuvimos de conocerle}

Gema López. Directora del Servicio de Terapias y Atención Familiar de la Fundación Quinta

Los profesionales que nos dedicamos al mundo del TEA tenemos una deuda impagable con él. No sólo por tener una mente privilegiada y ayudar a comprender el AUTISMO, sino también porque a nivel humano era una persona excepcional.

Tuve la suerte de formarme con él en el curso de intervención en autismo de APNA y ese curso cambió mi conocimiento del TEA y mi actividad profesional hasta el día de hoy.

Me quedo con las dos cosas que para mí han sido sus grandes enseñanzas:

- La necesidad de una comprensión profunda del trastorno para poder hacer una intervención de calidad. La necesidad de la formación de los profesionales que trabajamos en este mundo es primordial. Una formación completa y que pase 
por todas las facetas de la persona, basada en la COMPRENSIÓN, el RESPETO y el CARIÑO.

- La implicación personal del profesional, "Una intervención interna y comprometida y no ajena y externa de la intervención”. El profesional de TEA tiene que saber y sentir que hay que trabajar desde dentro, desde la persona, y estar convencido de que es la única manera y que además esto saca lo mejor de ti, no sólo como profesional, sino también como persona.

Se nos fue un grande, pero todo lo que nos dejó, sus enseñanzas siguen y seguirán con nosotros porque todavía nos queda mucho que aprender de él.

A mí me cambió de forma radical, "me configuró" de una manera, que creo que comparto con todos los que tuvimos la suerte de formarnos con él, que me acompañará a lo largo de mi vida profesional y personal.

Gracias, maestro. 